\title{
Appropriateness of referral of coronary angiography patients in Sweden
}

\author{
S J Bernstein, B Brorsson, T Åberg, H Emanuelsson, R H Brook, L Werkö, on behalf of \\ the SECOR/SBU Project Group
}

Keywords: coronary artery bypass graft surgery; angioplasty; quality of health care; health policy

\section{Objective-To evaluate the appropriate- ness of referral following coronary angio- graphy in Sweden. \\ Design-Prospective survey and review of medical records.}

Patients-Consecutive series of 2767 patients who underwent coronary angiography in Sweden between May 1994 and January 1995 and were considered for coronary revascularisation.

Main outcome measures-Percentage of patients referred for coronary artery bypass graft surgery (CABG) and percutaneous transluminal coronary angioplasty (PTCA) for indications that were judged necessary, appropriate, uncertain, and inappropriate by a multispecialty Swedish national expert panel using the RAND/University of California Los Angeles (UCLA) appropriateness method, and the percentage of patients referred for continued medical management who met necessity criteria for revascularisation.

Results-Half the patients were referred for CABG, $25 \%$ for PTCA, and $25 \%$ for continued medical therapy. CABG was judged appropriate or necessary for $78 \%$ of patients, uncertain for $12 \%$ and inappropriate for $10 \%$. For PTCA the figures were $32 \%, 30 \%$ and $38 \%$, respectively. Two factors contributed to the high inappropriate rate. Many of these patients did not have "significant" coronary artery disease (although all had at least one stenosis $>50 \%$ ) or they were treated with less than "optimal" medical therapy. While $96 \%$ of patients who met necessity criteria for revascularisation were appropriately referred for revascularisation, $4 \%$ were referred for continued medical therapy. Conclusions-Using the RAND/UCLA appropriateness method and the definitions agreed to by the expert panel, which may be considered conservative today, it was found that $19 \%$ of Swedish patients were referred for coronary revascularisation judged inappropriate. Since some cardiovascular procedures evolve rapidly, the proportion of patients referred for inappropriate indications today remains unknown. Nevertheless, physicians should actively identify those patients who will and will not benefit from coronary revascularisation and ensure that they are appropriately treated.

(Heart 1999;81:470-477)
Coronary artery bypass graft surgery (CABG) and percutaneous transluminal coronary angioplasty (PTCA) are two commonly used procedures that have been shown to relieve anginal symptoms in patients with coronary artery disease, ${ }^{1-9}$ and CABG has been shown to increase survival. ${ }^{10-12}$ Although these procedures are effective in select populations, the overall appropriateness of their use has been questioned. ${ }^{13-15}$

Sweden had one of the lower rates of use of bypass surgery and PTCA in western Europe until the early 1990s. By 1992, CABG was performed at a rate of 790 per million population and PTCA at a rate of 330 per million population. ${ }^{16}$ The CABG rate was second in western Europe, while the rate of use of PTCA was ranked eighth. These rates were approximately $50 \%$ and $25 \%$ of those in the United States, respectively.

This increase in the number of coronary revascularisation procedures and consequent costs caused the relevant Swedish specialist organisations to welcome an assessment of the benefits, risks, and outcomes of these developments proposed by an independent government agency, the Swedish Council for Technology Assessment in Health Care (SBU). The SBU chose to assess the degree of appropriateness of these interventions using the RAND appropriateness method. ${ }^{13}{ }^{14}$ While this study was being conducted it was reported that fewer than $1 \%$ of bypass surgeries and $5 \%$ of PTCAs in southwestern Sweden were inappropriate. ${ }^{17}$ However, the generalisability of those figures is questionable given that the data were almost entirely restricted to patients with chronic stable angina, who had a low-moderate operative risk and who did not have severe left ventricular dysfunction ${ }^{17}$ (A Bengtson, personal communication). In addition, the assessment of appropriateness of use of these procedures differed from most previous studies in the level of clinical detail used to judge appropriateness and the methods used to generate appropriateness criteria. In this report, we present data on how appropriately these procedures were used in community practice throughout Sweden in 1994.

\section{Methods}

DEVELOPMENT OF INDICATIONS AND APPROPRIATENESS CRITERIA

The indications and appropriateness criteria were developed using a modified Delphi process 
as developed by the RAND Corporation. ${ }^{18} 19$ The literature concerning the effectiveness and risks of CABG and PTCA from 1971 to March 1993 was reviewed and synthesised. ${ }^{20-22}$ Next a previously developed set of clinical scenarios, called indications, developed by a panel of US physicians and based on a literature review ${ }^{20}{ }^{21}$ was modified by a Swedish panel to represent all possible reasons for performing these procedures in Sweden. ${ }^{22}$

Each indication was formed by making a unique combination of clinical factors that were considered in recommending coronary revascularisation. These clinical factors included the extent of significant coronary artery disease, severity of angina, results of exercise stress tests, ejection fraction, adequacy of medical therapy, and the patient's surgical risk as assessed by the modified Parsonnet score. ${ }^{20}$ The indications were organised into groups according to the patient's presenting complaint-for example, chronic stable angina, unstable angina, recent myocardial infarction. The definitions for specific factors were developed and agreed on by the expert panel that later rated the indications for appropriateness. (See appendix A for a list of selected definitions.)

PANEL SELECTION AND APPROPRIATENESS

RATINGS

Nine expert clinicians were selected from nominations provided by the Swedish societies of cardiology, internal medicine, thoracic radiology, and thoracic surgery. Panelists were selected because of their clinical expertise. They represented all geographic regions of Sweden, performers and non-performers of the procedures, and both academic and nonacademic practice. The panel consisted of two cardiothoracic surgeons, one interventional cardiologist, three non-interventional cardiologists (one with special training in epidemiology), two cardiothoracic radiologists, and one internist. The panel met in October 1993.

Panelists were provided with literature reviews on both CABG and PTCA ${ }^{20-22}$ and asked to read these reviews and then rate each indication for the appropriateness of performing CABG, PTCA, or continued medical management considering an average patient presenting to either an average surgeon performing $\mathrm{CABG}$ or an average cardiologist performing PTCA in 1993. Appropriateness was defined as meaning that the expected health benefits exceeded the expected negative effects by a sufficiently wide margin that the procedure was worth doing. Appropriateness was rated on a 9 point scale with 1 being an extremely inappropriate indication and 9 being an extremely appropriate indication, with 5 assigned to those cases that were neither appropriate nor inappropriate.

The ratings took place in two rounds. The first was conducted independently at home by each panelist. The ratings were then tabulated and presented to the panelists at a second round attended by eight of the panelists. Each panelist received their own ratings and an anonymous distribution of the other panelists ratings. The panel reviewed the ratings, discussed and modified the definitions, and rated the indications again. The panel provided three ratings for each clinical scenario: the appropriateness of CABG compared to medical therapy, the appropriateness of PTCA compared to medical therapy, and the appropriateness of CABG compared to PTCA.

The final appropriateness rating was determined by the median of the nine panelists' second round ratings. An indication was appropriate if the median rating was 7 to 9 , inappropriate if the median rating was 1 to 3 , and uncertain if the median rating was 4 to 6 or if there was disagreement regardless of the median rating. Disagreement was defined as at least three panelists assigning a rating in the inappropriate range and three panelists assigning a rating in the appropriate range.

After determining indications that were appropriate for CABG or PTCA, the ratings were returned to the panel to rate the necessity of the procedure. ${ }^{23}$ The panelists were instructed to rate a procedure as necessary if it met the following four criteria: the procedure was appropriate without disagreement; the panelist believed it would be improper not to provide the service to the patient; there was a significant likelihood of benefit; and the degree of benefit was not small. Necessity ratings were also performed in two rounds in a manner identical to that described above for appropriateness. All nine panelists completed these ratings.

Two adjustments were made to the appropriateness ratings by the panel: (a) bypass surgery patients who had coronary artery disease amenable to treatment by PTCA, and for whom the panel judged PTCA more appropriate, were given a lower rating for CABG than the rating that would have applied if their coronary artery disease was not amenable to PTCA-for example, inappropriate if the CABG rating was uncertain when the patient had coronary artery disease amenable to PTCA; and (b) angioplasty patients for whom the panel judged CABG more appropriate than PTCA were given a lower rating than the rating that would have applied for PTCA compared with medical therapy - that is, inappropriate if the PTCA rating was uncertain when PTCA was compared with medical therapy.

An indication was then classified as being necessary, appropriate (but not necessary), uncertain in appropriateness, or inappropriate for PTCA or CABG. The literature review used by the panel, a listing of all 2002 indications, and the final panel appropriateness and necessity ratings have been published as a monograph available from SBU, Stockholm, Sweden. $^{22}$

DATA COLLECTION AND SAMPLE

We prospectively collected data on patients referred for consideration of coronary revascularisation to seven of the eight public Swedish heart centres that performed approximately $92 \%$ of all bypass surgeries in Sweden in 1994. The eighth heart centre declined to participate. We enrolled patients between May 1994 
Table 1 Sociodemographic characteristics of Swedish patients undergoing diagnostic coronary angiography* by the treatment or intervention to which they were referred

\begin{tabular}{|c|c|c|c|c|}
\hline Characteristics & $\begin{array}{l}\text { All patients } \\
(n=2767)\end{array}$ & $\begin{array}{l}\text { CABG patients } \\
(n=1387)\end{array}$ & $\begin{array}{l}\text { PTCA patients } \\
(n=687)\end{array}$ & $\begin{array}{l}\text { Medical treatment } \\
\text { patients }(n=693)\end{array}$ \\
\hline \multicolumn{5}{|l|}{ Age (\%) } \\
\hline $25-44$ years & 4.8 & 1.9 & 6.4 & 9.1 \\
\hline $45-54$ years & 19.1 & 11.9 & 24.5 & 28.1 \\
\hline $55-64$ years & 30.4 & 29.2 & 31.2 & 32.2 \\
\hline $65-74$ years & 37.2 & 45.9 & 32.5 & 24.4 \\
\hline$\geqslant 75$ years & 8.5 & 11.1 & 5.5 & 6.2 \\
\hline Median age (years) & 63 & 66 & 60 & 59 \\
\hline Male (\%) & 71.3 & 78.5 & 72.9 & 55.4 \\
\hline \multicolumn{5}{|l|}{ Anatomic diseaset (\%) } \\
\hline Left main & 10.7 & 20.6 & 0.3 & 1.0 \\
\hline Three vessels & 28.5 & 50.0 & 7.9 & 5.8 \\
\hline Two vessels with PLAD $\ddagger$ & 8.3 & 10.5 & 9.9 & 2.2 \\
\hline Two vessels, other & 12.6 & 12.0 & 20.5 & 5.8 \\
\hline Single vessel, with PLAD $\ddagger$ & 5.9 & 1.9 & 17.5 & 2.6 \\
\hline Single vessel, other & 12.4 & 3.0 & 34.1 & 9.5 \\
\hline \multicolumn{5}{|l|}{ Insignificant disease (\%) } \\
\hline $50-69 \%$ stenosis & 5.6 & 1.9 & 9.9 & 8.8 \\
\hline$<50 \%$ stenosis & 16.2 & 0 & 0 & 64.4 \\
\hline \multicolumn{5}{|l|}{ Clinical indication (\%) } \\
\hline Asymptomatic & 3.2 & 2.0 & 1.3 & 7.5 \\
\hline Chronic stable angina & 73.3 & 74.8 & 65.1 & 78.4 \\
\hline Unstable angina & 15.4 & 14.7 & 21.8 & 10.5 \\
\hline Postmyocardial infarction & 8.1 & 8.4 & 11.8 & 3.6 \\
\hline \multicolumn{5}{|l|}{ History of myocardial } \\
\hline infarction (\%) & 43.1 & 52.2 & 40.2 & 27.3 \\
\hline
\end{tabular}

*Patients were excluded from the study if they were being evaluated for arrhythmia, congestive heart failure, valvar heart disease or heart transplantation, if they were referred for emergency coronary angiography, had a history of PTCA within six months or any previous CABG or were enrolled in another study.

†See appendix A for definition of significant coronary artery disease.

$\ddagger$ PLAD (proximal left anterior descending) artery stenosis is defined as an obstruction before the first septal perforator. who performed the angiography and determined the severity of coronary artery stenosis then added these results to the data collection form. These data and the coronary angiogram were then reviewed at a cardiology conference usually attended by at least one cardiothoracic surgeon, one interventional cardiologist, and the referring cardiologist. Cardiology conferences are held at each of the heart centres and the composition of the conference is similar. Following the review of the case, a recommendation is made for the patient to be referred for CABG, PTCA, or continued medical therapy and entered on the data collection form. If CABG or PTCA is recommended, the priority of the intervention is also provided. The patient's physician then discusses the recommendation with the patient. A patient may agree with or decline the recommendation. Data were reviewed for completeness and accuracy before being entered into the computerised database.

\section{ANALYSIS}

Each patient referred for coronary revascularisation was assigned to a specific clinical chapter (for example, chronic stable angina), indication, and appropriateness ratings. Patients referred for continued medical management were assigned to a specific chapter and to two potential indications, one for CABG and one for PTCA. Based on these indications the necessity of revascularisation was determined. If either procedure was considered necessary then the patient was considered to have a necessary indication for revascularisation; if neither procedure was considered necessary then the patient was considered not to have a necessary indication.

Categorical variables were analysed by the $\chi^{2}$ statistic using STATA 5.0 on a personal computer.

\section{Results}

The heart conference committee referred 50\% of patients for CABG, 25\% for PTCA, and $25 \%$ for continued medical therapy (table 1). Patients referred for bypass surgery were older and there was a higher proportion of men compared to those referred for PTCA or medical therapy. Seventy one per cent of the patients referred for bypass operations had either left main disease or three vessel disease. Fewer than $7 \%$ of bypass patients had single vessel or insignificant disease (see appendix A for list of definitions). Among PTCA patients more than half had single vessel disease. All patients referred for revascularisation had at least one vessel with a minimum stenosis of $50 \%$ or greater. In contrast, almost three quarters of those patients referred for continued medical therapy had insignificant disease.

Eighty eight per cent of patients undergoing coronary angiography presented with either chronic stable angina (73\%) or unstable angina $(15 \%)$. Although chronic stable angina was the most common indication in all three referral groups, PTCA patients more often presented with unstable angina than either the bypass surgery or the continued medical therapy 
Table 2 Appropriateness of coronary revascularisation for coronary angiography patients in Sweden in 1994, by the treatment or intervention to which they were referred

\begin{tabular}{lrllll}
\hline & \multicolumn{5}{c}{ Appropriateness of coronary revascularisation (\%) } \\
\cline { 3 - 6 } Referral & $n$ & $\begin{array}{l}\text { Appropriate and } \\
\text { necessary }\end{array}$ & Appropriate & Uncertain & Inappropriate \\
\hline CABG & 1387 & 77.6 & 0.4 & 12.3 & 9.7 \\
PTCA & 687 & 21.3 & 10.5 & 30.0 & 38.3 \\
Medical & 693 & 8.2 & - & - & - \\
\hline
\end{tabular}

${ }^{\star}$ For patients referred for continued medical therapy we only determined the necessity of undergoing coronary revascularisation.

patients $(\mathrm{p}<0.001)$. PTCA patients were also more likely to present following myocardial infarction than patients referred for bypass surgery or continued medical therapy $(\mathrm{p}<0.001)$. A history of a myocardial infarction was present in $50 \%$ of bypass candidates compared to $40 \%$ of PTCA candidates and $25 \%$ of those patients referred for continued medical management $(\mathrm{p}<0.001)$. In contrast, $6 \%$ of bypass surgery patients were classified as being at high risk for an operative complication compared to $3 \%$ of patients in the other two groups

APPROPRIATENESS OF CABG

Among patients referred for bypass surgery $78 \%$ of the cases were classified as appropriate and necessary, $12 \%$ as uncertain, and $10 \%$ as inappropriate (table 2). Of the 704 possible scenarios, 164 were used in this sample of 1387 cases. Eight scenarios accounted for $50 \%$ of the cases. The most frequent necessary, appropriate, uncertain, and inappropriate indications are shown in table 3.

Inappropriate referrals had several important features. First, many patients were treated with less than maximal medication. Seventy nine of the 88 chronic stable angina patients who were referred for CABG that was considered inappropriate had received less than "optimal" medical therapy. Second, in some cases the panel believed that revascularisation was appropriate but that PTCA was preferred. Forty nine of the patients referred for bypass surgery considered inappropriate would have been rated as appropriate or uncertain if PTCA had not been available. Finally, 26 of these patients did not fulfill criteria for "significant" coronary artery disease, although all of these patients had at least one vessel with a minimum stenosis of $50 \%$.

APPROPRIATENESS OF PTCA

Almost a third of the referrals for PTCA were judged appropriate or necessary, 30\% uncertain, and $38 \%$ inappropriate. One hundred and forty two of the 704 possible scenarios were used to rate the 687 cases. The characteristics of PTCA cases judged inappropriate had some similarities and differences from those for CABG. There were four factors contributing to the high inappropriate rate. Many of these patients were treated with less than "optimal" medical therapy (for example, $86 \%$ of the chronic stable angina patients referred for PTCAs judged inappropriate were treated with less than "optimal" medical therapy). Second, a quarter of patients were considered to have coronary artery disease better treated by bypass surgery (for example, left main or three vessel disease, or type C lesions). Third, another quarter of patients who were referred for a PTCA that was judged inappropriate did not fulfill the criteria for "significant" coronary artery disease. Finally, $17 \%$ of the patients who were referred for a PTCA judged inappropriate had single vessel disease not involving the proximal left anterior descending artery and did not have a very positive stress test. The most common indications are shown in table 4 .

\section{APPROPRIATENESS OF MEDICAL MANAGEMENT}

Among those patients referred for continued medical therapy, 57 patients $(8.2 \%)$ met necessity criteria for coronary revascularisation. Forty seven of these patients $(82 \%)$ had chronic stable angina. There were seven patients with left main coronary artery disease, 30 with three vessel disease, seven with two vessel disease with proximal left anterior

Table 3 Most frequently used CABG indications by appropriateness category

\begin{tabular}{|c|c|c|}
\hline Indication & $n$ & $\begin{array}{l}\text { Appropriateness } \\
\text { rating }\end{array}$ \\
\hline \multicolumn{3}{|l|}{ Necessary } \\
\hline $\begin{array}{l}\text { Severe chronic stable angina (class III/IV) treated with less than "optimal" medical therapy, three vessel disease with a type C lesion, } \\
\text { an ejection fraction }>20 \% \text {, in a patient with a low to moderate operative risk }\end{array}$ & 178 & 8 \\
\hline $\begin{array}{l}\text { Severe chronic stable angina (class III/IV) treated with less than "optimal" medical therapy, left main coronary artery disease, with an } \\
\text { ejection fraction }>20 \% \text {, in a patient with a low to moderate operative risk }\end{array}$ & 115 & 9 \\
\hline $\begin{array}{l}\text { Mild or moderate angina chronic stable angina (class } \mathrm{I} / \mathrm{II} \text { ) treated with less than "optimal" medical therapy, with three vessel disease } \\
\text { with a type C lesion, with an ejection fraction }>20 \% \text {, in a patient who has a low to moderate operative risk }\end{array}$ & 107 & 7 \\
\hline \multicolumn{3}{|l|}{ Appropriate } \\
\hline $\begin{array}{l}\text { Patient has continuing pain between } 1 \text { and } 21 \text { days after an acute myocardial infarction while treated with less than "optimal" } \\
\text { medical therapy, three vessel disease with a type C lesion, an ejection fraction }>20 \% \text {, in a patient with a low to moderate operative } \\
\text { risk }\end{array}$ & 5 & 7 \\
\hline \multicolumn{3}{|l|}{ Uncertain } \\
\hline $\begin{array}{l}\text { Severe chronic stable angina (class III/IV) treated with less than "optimal" medical therapy, with two vessel non-proximal left anterior } \\
\text { descending artery disease with a type C lesion, in a patient with a very positive stress test, an ejection fraction }>20 \% \text {, who has a low }\end{array}$ & & \\
\hline to moderate operative risk & 27 & 5.5 \\
\hline $\begin{array}{l}\text { Mild or moderate angina chronic stable angina (class I/II) treated with less than "optimal" medical therapy, with two vessel } \\
\text { non-proximal left anterior descending artery disease with a type C lesion, in a patient with a very positive stress test, an ejection }\end{array}$ & & \\
\hline fraction $>20 \%$, who has a low to moderate operative risk & 20 & 5 \\
\hline \multicolumn{3}{|l|}{ Inappropriate } \\
\hline Chronic stable angina without "significant" coronary artery disease & 21 & 1 \\
\hline $\begin{array}{l}\text { Mild or moderate angina chronic stable angina (class I/II) treated with less than "optimal" medical therapy, with two vessel } \\
\text { non-proximal left anterior descending artery disease with a type A or B lesion, in a patient with a very positive stress test, an ejection } \\
\text { fraction }>20 \% \text {, who has a low to moderate operative risk }\end{array}$ & 10 & 3 \\
\hline
\end{tabular}

*The expert panel judged any revascularisation procedure in patients without "significant" coronary artery disease as inappropriate without further classification of symptoms 
Table 4 Most frequently used PTCA indications by appropriateness category

\begin{tabular}{|c|c|c|}
\hline Indications & $n$ & $\begin{array}{l}\text { Appropriateness } \\
\text { rating }\end{array}$ \\
\hline \multicolumn{3}{|l|}{ Necessary } \\
\hline $\begin{array}{l}\text { Patient has continuing pain between } 1 \text { and } 21 \text { days of an acute myocardial infarction while treated with "optimal" medical therapy, single } \\
\text { vessel non-PLAD disease with a type A or B lesion, an ejection fraction }>20 \% \text {, and a low to moderate operative risk }\end{array}$ & 15 & 9 \\
\hline $\begin{array}{l}\text { Severe chronic stable angina (class III/IV) treated with less than "optimal" medical therapy, with two vessel disease involving the PLAD } \\
\text { with a type C lesion, with a very positive stress test, an ejection fraction }>20 \% \text {, and a low to moderate operative risk }\end{array}$ & 13 & 8 \\
\hline \multicolumn{3}{|l|}{ Appropriate } \\
\hline $\begin{array}{l}\text { Severe chronic stable angina (class III/IV) treated with less than "optimal" medical therapy, with two vessel non-PLAD disease with a } \\
\text { type A or B lesion, without a very positive stress test, an ejection fraction }>20 \% \text {, and a low to moderate operative risk } \\
\text { Severe chronic stable angina (class III/IV) treated with less than "optimal" medical therapy, with one vessel coronary artery disease } \\
\text { involving the PLAD with a type A or B lesion, with a very positive stress test, an ejection fraction }>20 \% \text {, and a low to moderate }\end{array}$ & 23 & 7 \\
\hline \multicolumn{3}{|l|}{ Uncertain } \\
\hline Mild or moderate chronic stable angina (class I/II) treated with less than "optimal" medical therapy, with single vessel non-proximal & & \\
\hline $\begin{array}{l}\text { left anterior descending artery disease with a type A or B lesion, in a patient with a very positive stress test, an ejection fraction }>20 \% \text {, } \\
\text { who has a low to moderate operative risk }\end{array}$ & 24 & 5 \\
\hline Severe chronic stable angina (class III/IV) on less than "optimal" medical therapy, with one vessel non-PLAD disease with a type A or & & \\
\hline B lesion, a very positive stress test, an ejection fraction $>20 \%$, and a low to moderate operative risk & 18 & 6 \\
\hline \multicolumn{3}{|l|}{ Inappropriate } \\
\hline Chronic stable angina without "significant" coronary artery disease & 54 & 1 \\
\hline $\begin{array}{l}\text { Severe chronic stable angina (class III/IV) treated with less than "optimal" medical therapy, one vessel non-PLAD disease with a type A } \\
\text { or B lesion, without a very positive stress test, an ejection fraction }>20 \% \text {, and a low to moderate operative risk }\end{array}$ & 20 & 3 \\
\hline
\end{tabular}

PLAD, proximal left anterior descending.

descending artery involvement, and the remaining 13 patients had less severe disease.

COMPARISON BETWEEN SWEDISH NATIONAL STUDY IN 1994 AND GÖTEBORG 1990 TO 1991 The present study examined a national sample of Swedish patients referred for coronary angiography in 1994, approximately two thirds of whom had chronic stable angina. A previous study of chronic stable angina patients referred for CABG in southwestern Sweden in 1991, by Bengtson et al, reported that only $1 \%$ of cases were considered inappropriate, $8 \%$ uncertain, and $92 \%$ appropriate. ${ }^{17}$ Similarly, $86 \%$ of PTCAs performed in southwestern Sweden in 1991 were reported to be appropriate, 9\% uncertain in appropriateness, and 5\% inappropriate. These ratings were significantly better than those found in this study for chronic stable angina patients referred for CABG or

Table 5 Appropriateness of referral for coronary revascularisation in Sweden in 1994 by procedure and clinical indications chapter

\begin{tabular}{lrlllr}
\hline \multicolumn{5}{c}{ Appropriateness (\%) } \\
\cline { 3 - 6 } Indication & $n$ & $\begin{array}{l}\text { Appropriate } \\
\text { and necessary }\end{array}$ & Appropriate & Uncertain & Inappropriate \\
\hline CABG & 28 & 64.3 & 0 & 21.4 & 14.3 \\
$\quad$ Asymptomatic & 1038 & 78.3 & 0 & 13.2 & 8.5 \\
Chronic stable angina & 204 & 73.0 & 0 & 10.3 & 16.7 \\
Unstable angina & 117 & 82.1 & 5.1 & 6.0 & 6.8 \\
Postmyocardial infarction & & 0 & 0 & 44.4 & 55.6 \\
PTCA & 94 & 12.3 & 13.2 & 37.8 & 36.7 \\
Asymptomatic & 150 & 24.7 & 6.7 & 12.7 & 56.0 \\
Chronic stable angina & 81 & 66.7 & 3.7 & 17.3 & 12.4 \\
Unstable angina & Postmyocardial infarction & & & &
\end{tabular}

Table 6 Appropriateness of referral for coronary revascularisation for chronic stable angina patients in southwestern Sweden in 1994 by procedure and source of appropriateness rating ${ }^{\star}$

\begin{tabular}{llll}
\hline & \multicolumn{3}{l}{ Appropriateness of coronary revascularisation (\%) } \\
\cline { 2 - 4 } Source of appropriateness rating & Appropriate & Uncertain & Inappropriate \\
\hline CABG (n = 181) & & & \\
1990 Göteborg criteria & 66.9 & 28.7 & 4.4 \\
1994 national panel & 85.6 & 9.4 & 5.0 \\
PTCA (n = 98) & 49.0 & 26.5 & 24.5 \\
1990 Göteborg criteria & 32.7 & 33.7 & 33.7 \\
1994 national panel & & & \\
\hline
\end{tabular}

^A Bengtson, personal communication, 1997.
PTCA where the inappropriate rate of use was approximately eight fold higher (table 5) ( $\mathrm{p}<0.001$ for both comparisons).

Since patients from the entire country were included in our study, and Bengtson's study only included patients from southwestern Sweden, we identified those patients in our dataset who were cared for in the same southwestern Swedish hospitals as in Bengtson's study. We also restricted the comparison to patients with low to moderate operative risk and who were without severe left ventricular dysfunction, the same characteristics as the original population described by Bengtson et al (A Bengtson, personal communication). We then applied both Bengtson's criteria and that of the Swedish national expert panel to our dataset (table 6 ). We found that the national panel's criteria judged a greater proportion of CABG cases appropriate $(85.6 \% \quad v 66.9 \%)$ and a similar proportion inappropriate $(5.0 \% v 4.4 \%)$. For PTCA, the national expert panel's criteria judged fewer cases appropriate $(32.7 \% v 49 \%)$ and more inappropriate $(33.7 \%$ v $24.5 \%)$.

\section{Discussion}

We studied the appropriateness of referral of coronary angiography patients in Sweden in 1994. Approximately $10 \%$ of the referrals for bypass surgery and almost $40 \%$ of the referrals for PTCA were considered inappropriate. Three factors accounted for the high inappropriate rate: operations on arteries without "significant" coronary artery disease, operations on patients who were treated with less than "optimal" doses of medications, and the choice of the "wrong" revascularisation procedure.

The primary goals of coronary revascularisation are to relieve angina, improve the quality of life, and reduce the probability of dying for patients with coronary artery disease. Thus the use of these procedures in patients with stenoses between $50 \%$ and $69 \%$, which were considered to be less than "significant" disease, may either represent their physician's attempt to relieve symptoms or treatment of patients with more severe disease that has been misread as "insignificant". 
Among all patients referred for coronary revascularisation, two thirds were classified as receiving less than "optimal" doses of medications. Why did so few patients receive "optimal" medications? The Swedish panel set extremely high standards that might not be accepted in other countries or even by other physicians within Sweden. For example, the panel required a chronic stable angina patient to be on a $\beta$ blocker, calcium channel blocker, and a nitrate (as long as there were no contraindications) in order to be classified as receiving "optimal" medication. Expert physician panels in the $\mathrm{US}^{13}$ and Canada ${ }^{24}$ defined maximal medical treatment as a patient receiving only two of these three medications. Swedish funding restrictions and concomitant lower rates of use of coronary revascularisation may have led the Swedish panel to attempt to maximise medical treatment before referring a patient for a scarce procedure. In practice, however, Swedish physicians may apply a lower threshold. In this study, half the chronic stable angina patients referred for coronary revascularisation had been treated only with two antianginal medications.

Finally, some bypass referrals were rated inappropriate in patients with one or two vessel disease because the panel believed that the better procedure to perform in these patients was PTCA. This may reflect patient or physician preference, local waiting times, and the lack (at the time the study was being conducted) of much information comparing the efficacy of CABG versus PTCA in patients whose anatomy was amenable to both procedures.

The difference in findings between the 1991 southwestern Swedish data and our own is troubling. Even when using Bengtson's criteria we still found a four to fivefold higher inappropriate rate for patients cared for in the same hospitals within a four year period. This is not a trivial difference. One possible explanation for these findings is that our data are based on patients being referred for coronary revascularisation while the 1991 data were based on patients who were on a waiting list for coronary revascularisation. A patient's clinical condition may change as they wait and thus the appropriateness rating they received at the time they were referred for the procedure may no longer apply. This may occur in Sweden as the median waiting time for chronic stable angina patients for bypass surgery was 59 days. ${ }^{25}$ In the Netherlands, we previously found that the urgency of revascularisation changed for $9 \%$ of chronic stable angina patients on a waiting list for $\mathrm{CABG}$ and for $5 \%$ of patients on a waiting list for PTCA. ${ }^{25}$ To determine how appropriately these procedures are being used would require assessment of the appropriateness at the time of the revascularisation procedure.

It is important to consider the results of this study in relation to other recent studies examining the appropriateness of use of cardiovascular procedures in the US, Canada, and the Netherlands. ${ }^{13} 142425$ It is noteworthy that across all four studies the appropriateness of referral to or use of bypass surgery has been uniformly high, with the inappropriate rate under $10 \%$. This is not surprising given that most of the patients referred for bypass surgery had left main or three vessel disease. In contrast, many PTCA cases were judged uncertain or inappropriate. We found that $68 \%$ of referrals for PTCAs were uncertain in appropriateness or inappropriate. This finding is similar to the $60 \%$ rate in the Netherlands and $42 \%$ rate in the State of New York. A key reason for this finding was that there were limited data regarding the indications for PTCA when all these studies were being conducted. For example, there were no randomised controlled trials comparing PTCA and bypass surgery and only one such trial comparing PTCA and medical therapy when these criteria were established. Findings from our study can be used to highlight areas of uncertainty in clinical decision making and provide a focus for future clinical trials. It also shows that uncertainty is not confined to a single country but represents uncertainty among physicians in several countries.

Our study does have two limitations. First, the large number of cases with insignificant coronary artery disease raises questions as to the quality of the interpretation of the angiogram and the definition of "significant" coronary artery stenosis. It has been well documented that the accuracy of visual interpretation is only fair ${ }^{26-28}$ and that there is considerable intra- and interobserver variability. In addition, the definition used by clinicians to define "significant" stenoses may be changing. At the time our panel met, the standard practice was for clinicians to assess subjectively the severity of the stenosis, and the definition of "significant" stenosis included either a 50\% reduction in left main coronary artery diameter or a $70 \%$ obstruction in another major cardiac artery. Today, many cardiologists are using a lower threshold to define "significant" stenosis (for example, $>50 \%$ stenosis in any major cardiac artery). If such a change began diffusing into practice during the time our study was in progress, there may have been some misclassification of cases. Second, PTCA has had a very slow dissemination process in Sweden and the use of PTCA in 1994 may not reflect current practice patterns. Advances in medical practice have occurred since that time and information is now available regarding the efficacy of PTCA and related therapies (for example, intracoronary stents) that were lacking when the panel first met. This type of rapid evolution presents a challenge to clinicians and others in evaluating these technologies and trying to assure their appropriate utilisation.

In summary, there does not appear to be overuse of bypass surgery in Sweden. PTCA is frequently performed for uncertain or inappropriate indications, primarily reflecting the lack of high quality data regarding outcomes of this intervention. Of those patients who met necessity criteria for revascularisation, 96\% were appropriately referred for CABG or PTCA. However, $8 \%$ of patients who were referred for continued medical therapy also met necessity criteria. We would expect that patients who meet necessity criteria and do not undergo 
revascularisation would have worse outcomes then those who do not. ${ }^{29}$ The specific reason these patients were not referred for revascularisation remains unclear and there may have been extenuating circumstances. These issues needed to be further examined.

We believe these findings are important for policy makers as they contemplate whether to expand resources for cardiovascular care in Sweden. Data such as these can provide physicians, patients, and the government with information needed to make better decisions. Our finding that a small number of Swedish patients were not referred for a procedure judged to be necessary was disturbing.

One approach would be to update the Swedish national expert panel criteria, as needed to reflect current knowledge, and apply it prospectively as part of the continuing process which identifies those patients who should undergo coronary angiography and need coronary revascularisation. The resulting recommendation for CABG, PTCA, or continued medical therapy would be given to the patient and their physician. The patient and physician would then make their treatment choice; however, if they disagreed with the national criteria they would be required to explain why the criteria were not applicable in that specific case. Sweden would then be at the forefront of efforts to improve the quality of care received by its citizens by assuring that overuse and underuse of coronary revascularisation procedures were minimised.

The SECOR/SBU project was supported by grants from the Swedish Medical Research Council and the Swedish Federation of Country Councils. We are especially grateful to the 2767 patients who agreed to participate in this study. We thank AnnSofie Nord who coordinated data collection at SBU and Ann
Bengtson for reviewing the method used by her group in their Bengtson for reviewing the method used by her group in their
1991 study. We also appreciated the assistance of Barbara Genovese and R Edward Park with data processing and Christine Moore with manuscript preparation. Finally, we thank the physicians who served on the expert panel that developed the indications and the ratings: Lars Ekström, Thomas Kjellström, Nina Rehnqvist, Kurt Svärdsudd, Torkel Åberg, Torbjörn Ivert, Carl Lamm, Helge Saetre, and Mats Velander. SECOR/SBU project group: Lars Werkö (chairman), Bengt Brorsson (principal group: Lars Werko (chairman), Bengt Brorsson (principal investigator), Nina Rehnqvist, Olof Edhag, Hakan Emanuelsson, Ulf Haglund, Kjell Rådegran, Göran Stenport, Egon Jonsson, Gunilla Lamnevik, Torkel Åberg. SECOR/SBU investigators: Carl Gunnar Gustavsson, Carina Wendel (Lund University Hospital), Lars Ohlsson (deceased), Mikael Kehler (Karlskrona Hospital), Kjell Jansson, Christina Wikström (Linköping University Hospital), Per Albertsson, Marie Carlsson (Sahlgrenska University Hospital, Östra Hospital, Skövde Hospital Uddevalla Hospital, Norra Älvsborg Hospital, Borås Hospital and Varberg Hospital), Stella Scizinsky, Gunilla Forsell, Birgitta Grape (Karolinska University Hospital), Carl-Göran Ericsson, Margret Lundström (Danderyd Hospital), Inger Axelsson, Cur Thorstrand (South Hospital), Bo Lindvall (Huddinge University Hospital), Christina Stafberg, Lena Jideus, Jenny Kjellgren Uppsala University Hospital), Helge Saetre, Britt-Marie Nilsson (Falu Hospital), Stellan Bandh, Inger Alexandersson (Västerås Hospital), Gunnar Gustafsson (Gävle Hospital), Jan Hellström, Hans Petter Ildgruben, Margaretha Ritfeldh (Norrland University Hospital), Håkan Forsberg, Birgitta Palmreidh (Boden Hospital), Bengt Möller, Carina Lundblom (Sundsvall Hospital).

\section{Appendix A: Selected list of definitions developed by the Swedish expert panel} "Significant" coronary artery disease was defined as: left main coronary artery disease if there was $\geqslant 50 \%$ stenosis of the left main coronary artery; multivessel disease if there was $\geqslant 70 \%$ stenosis in one major artery and $\geqslant 50 \%$ stenosis in other arteries (excluding left main disease); or single vessel disease if there was $\geqslant 70 \%$ stenosis in one major artery (excluding left main disease).

"Optimal" medical therapy was defined separately for patients with chronic stable angina, unstable angina, and following a myocardial infarction (days 1-21). The definitions were as follows.

Chronic stable angina-the patient must receive: (a) one drug from each of the three major classes of antianginal medications (a long acting nitrate, $\beta$ blocker, and calcium channel blocker); or (b) has received two of the three classes of medication and has a contraindication (for example, a patient with asthma may not be a candidate for $\beta$ blockers) or intolerance to the remaining medications; or (c) has received one class of medication and has a contraindication or intolerance to the remaining two classes of medications; or (d) has a contraindication or intolerance to all three classes of medications.

Unstable angina - the patient must receive: (a) four of the following five classes of medications (long acting nitrates, $\beta$ blockers, calcium channel blockers, intravenous heparin, intravenous nitroglycerin); or (b) has received three of the five classes of medication and has a contraindication or intolerance to the remaining categories of medications; or (c) has received two of the five classes of medication and has a contraindication or intolerance to the remaining categories of medications; or (d) has received one of the five classes of medication and has a contraindication or intolerance to the remaining categories of medications; or (e) has received no medication because of a contraindication or intolerance to all classes of medications.

Following myocardial infarction (days 1-21) - the patient must receive aspirin (unless contraindicated) and two of the three major classes of antianginal medications (a long acting nitrate, $\beta$ blocker, and calcium channel blocker) or one of the three classes of medication if he or she has a contraindication or intolerance to the remaining medications or intravenous nitroglycerin, or has a contraindication to all of these medications.

"High" surgical risk was defined as a score of 19 or more on the modified Parsonnet index. ${ }^{20}$

1 CABRI Trial Participants. First-year results of CABRI (coronary angioplasty vs bypass revascularization investigation). Lancet 1995;346:1179-84.

2 RITA Trial Participants. Coronary angioplasty versus coronary artery bypass surgery: the randomized intervention treatment of angina (RITA) trial. Lancet 1993;341: tion treat 80.

3 King SB, Lemno NJ, Kosinski AS, et al. A randomized trial comparing coronary angioplasty with coronary artery comparing coronary angioplasty with coronary
bypass surgery. $N$ Engl $\mathcal{F}$ Med $1994 ; 331: 1044-50$

4 Hamm CW, Riemers J, Ischinger T, et al. A randomized study of coronary angioplasty compared with bypass surgery in patients with symptomatic multi-vessel coronary disease. N Engl F Med 1994;331:1037-43.

5 Carrie D, Elbaz M, Puel J, et al. Five-year outcome after coronary angioplasty versus bypass surgery in multivessel coronary artery disease: results from the French monocentric study. Circulation 1997;96(suppl):II-1-6.

6 Hueb W, Arie S, Oliveira SA, et al. The medicine, angioplasty or surgery study (MASS): a prospective randomized trial of medical therapy, balloon angioplasty or randomized trial of medical therapy, balloon angioplasty or bypass surgery for single proximal left ante

7 Goy JJ, Eeckhout E, Burnand B, et al. Coronary angioplasty versus left internal mammary grafting for isolated proximal 1449-53. 
8 Rodriguez A, Boullon F, Perez-Balino N, et al. Argentine randomized trial of percutaneous transluminal coronary angioplasty versus coronary artery bypass surgery in multivessel disease (ERACI): in-hospital results and 1-year follow-up. 7 Am Coll Cardiol 1993;22:1060-7.

9 BARI Investigators. Comparison of coronary bypass surgery with angioplasty in patients with multivessel disease. $N$ Engl F Med 1996;335:217-25.

10 CASS Principal Investigators and their Associates. Coronary artery surgery study (CASS): a randomized trial of coronary artery bypass surgery. Circulation 1983;68:939-50.

11 Varnauskas E. Twelve year follow-up of survival in the randomized European coronary surgery study. $N$ Engl f Med 1988;319:332-7.

12 Veterans' Administration Coronary Artery Bypass Surgery Cooperative Study Group. Eleven-year survival in the Veterans' Administration randomized trial of coronary bypass surgery for stable angina. N Engl f Med 1984;311:1333-9.

13 Leape LL, Hilborne LH, Park RE, et al. The appropriateness of use of coronary artery bypass graft surgery in New ness of use of coronary artery bypass

14 Hilborne LH, Leape LL, Bernstein SJ, et al. The appropriateness of use of percutaneous transluminal coronary angioplasty in New York State. FAMA 1993;269:761-5

15 Rigter H, Meijler AP, McDonnell J, et al. Indications for coronary revascularization: a Dutch perspective. Hear 1997;77:211-18

16 Health Council of the Netherlands Committee. Heart surgery and interventional cardiology for adults. The Hague: Health Council of the Netherlands; publication no. 1995/01E, 1995.

17 Bengtson A, Herlitz J, Karlsson T, et al. The appropriateness of performing coronary angiography and coronary artery revascularization in a Swedish population. $7 A M A 1994$ 271:1260-5.

18 Park E, Fink A, Brook RH, et al. Physician ratings of appropriate indications for six medical and surgical procedures. priate indications for six medical and

19 Shekelle PG, Kahan JP, Bernstein SJ, et al. The reproducibility of a method to identify the overuse and underuse of medical procedures. N Engl f Med 1998;338:1888-95.
20 Hilborne LH, Leape LL, Kahan JP, et al. Percutaneous transluminal coronary angioplasty: a literature review and atings of appropriateness and necessity. Santa Monica, California: RAND, publication JRA-01, 1991.

21 Leape LL, Hilborne LH, Kahan JP, et al. Coronary artery bypass graft: a literature review and ratings of appropriateness and necessity. Santa Monica, California: RAND, publication JRA-02, 1991.

22 Johansson SR, Brorsson B, Bernstein SJ. Coronary artery bypass graft and percutaneous transluminal coronary angioplasty: a literature review and ratings of appropriateness and necessity. SBU report no. 120E. Stockholm, Sweden: The Swedish Council on Technology Assessment in Health Care, 1994.

23 Kahan JP, Bernstein SJ, Leape LL, et al. Measuring the necessity of medical procedures. Med Care 1994;32:35765.

24 Naylor CD, McGlynn EA, Leape LL, et al. Coronary angiography and revascularization: defining procedural indications through formal group process. Can 7 Cardiol 1994:10:41-8.

25 Bernstein SJ, Rigter H, Brorsson B, et al. Waiting for coronary revascularization: a comparision between New York State, the Netherlands and Sweden. Health Policy 1997;42: $15-27$.

26 Detre KM, Wright E, Murphy ML, et al. Observer agreement in evaluating coronary angiograms. Circulation 1975;52:979-86.

27 Fisher LD, Judkins MP, Lesperance J, et al. Reproducibility of coronary arteriographic reading in the coronary artery surgery study (CASS). Cathet Cardiovasc Diagn 1982;8: $565-75$.

28 Kussmaul WG, Popp RL, Norcini J. Accuracy and reproducibility of visual coronary stenosis estimates using information from multiple observers. Clinical Cardiology 1992;15:154-62.

29 Kravitz R, Laouri M, Kahan JP, et al. Validity of criteria used for detecting underuse of coronary revascularization. fAMA 1995;274:632-8. 